\title{
Influence of Compression Ratio Differences between Magnetic Resonance Images and Simple Radiographs on Osteoporotic Vertebral Compression Fracture Prognosis after Vertebroplasty
}

\author{
Si-Hoon Lee, Sang-Gu Lee, Seong Son, Woo-Kyung Kim \\ Department of Neurosurgery, Gachon University, Gil Medical Center, Incheon, Korea
}

Objective: The extent of collapse progression after vertebroplasty in osteoporotic vertebral compression fractures (OVCF) has known to be various. In this study, we investigated that how much difference of compression ratio between standing simple radiograph and supine magnetic resonance imaging (MRI) affects the collapse progression after vertebroplasty. Methods: This retrospective cohort study was carried out based on 27 patients with 31 OVCFs undergone vertebrplastyin the thoracolumbar junction (T12-L2), from January to December 2009. The OVCFs were divided to two groups, the smaller group A and larger group B, by mean compression ratio difference (8.1\%) between standing simple radiograph and supine MRI.

Results: There were no significant differences in the baseline characteristics of the two groups except age. There were also no significant differences between the periodic compression ratio, back pain, Cobb's angle during follow-up period. However, Group B seemed to show improvements from the initial state to the point just after the operation, but eventually took a much worse course than group A. In the end, judging from the compression ratios of the two groups at the last follow up, group A showed less progression.

Conclusion: Although the clinical outcome was not different significantly, a greater compression ratio difference in the initial study resulted in a greater collapse progression at last follow-up. Therefore, we suggest that it is important to check the initial standing simple radiograph, as well as supine MRI, for predicting collapse progression after vertebroplasty.

Key Words: Compression ratio $\cdot$ Osteoporotic compression fracture • Vertebroplasty

\section{INTRODUCTION}

Osteoporotic vertebral compression fracture (OVCF) can be defined as a clinical characteristic that is derived from the destruction of height of a fractured vertebral body, acute pain, and vertebral deformation. An OVCF is diagnosed when a progressive or newly generated compression fracture is identified on simple radiography or when a lesion is identified usingmagnetic resonance imaging (MRI), computed tomography

- Received: April 23, 2014 - Revised: June 5, 2014

- Accepted: June 9, 2014

Corresponding Author: Sang Gu Lee, MD, PhD

Department of Neurosurgery, Gachon University, Gil Medical Center, 24 Namdong-daero, 774 Beon-gil, Namdong-gu, Incheon 405-760, Korea Tel: +82-32-460-3304, Fax: +82-32-460-3899

E-mail: samddal@gilhospital.com

®This is an Open Access article distributed under the terms of the Creative Commons Attribution Non-Commercial License (http://creativecommons.org/ licenses/by-nc/3.0/) which permits unrestricted non-commercial use, distribution, and reproduction in any medium, provided the original work is properly cited.
(CT), or a bone scan. When no improvement is observed with conservative therapy after diagnosis, percutaneous vertebroplasty, balloon kyphoplasty, or surgery is performed. However, even if absolute stability is maintained during conservative therapy, progression of the compression fracture is often observed. Thus, in this study, we compared the significance of the difference in the compression ratio measured using radiograph in the standing position and MRI in the supine position at the site of initial OVCF with progression of compression fracture. The correlation between the progression of the compression ratio with the compression ratio difference of the two images, visual analog scale (VAS) score, bone mineral density (BMD), age, sex, and cement injection dose were also evaluated to determine the clinical significance.

\section{MATERIALS AND METHODS}

This study and included patients treated between January and December 2009 at a single spine center retrospectively. A total of 57 patients were diagnosed with osteoporotic verte- 
Table 1. Demographics

\begin{tabular}{ll}
\hline \hline \multicolumn{1}{c}{ Criteria } & Statistics, $\mathrm{M} \pm \mathrm{SD}, \mathrm{n}(\%)$ \\
\hline \hline Sex & \\
$\mathrm{M}$ & $7(22.6)$ \\
$\mathrm{F}$ & $24(77.4)$ \\
Age, years (range) & $73.0 \pm 7.1(58.0-88.0)$ \\
Initial radiography compression ratio (\%) & $28.4 \pm 13.7(3.0-59.0)$ \\
Preoperative MR image compression ratio (\%) & $20.4 \pm 12.9(1.0-47.0)$ \\
Radiograph-MR image compression ratio (\%) & $8.1 \pm 7.7(0.0-38.0)$ \\
BMD & $-3.2 \pm 1.2(-5.7$ to -1.3$)$ \\
Diagnosis to treatment period (days) & $13.0 \pm 5.1(1.0-18.0)$ \\
PMMA dosage (cc) & $4.16 \pm 0.69(2.00-6.00)$ \\
radiograph compression ratio at the vertebroplasty day (\%) & $29.8 \pm 12.7(4.0-48.0)$ \\
Radiograph compression ratio after 6 months (\%) & $36.2 \pm 13.5(12.0-64.0)$ \\
HTN & $19(61.3)$ \\
DM & $4(12.9)$ \\
Trauma & $24(77.4)$ \\
\hline
\end{tabular}

MRI, magnetic resonance imaging; $\mathrm{BMD}$, bone mineral density; PMMA, polymethylmethacrylate; OP, osteoporosis; $\mathrm{Hx}$, history; HTN, hypertension; DM, diabetes mellitus.

bral compression fractures and underwent percutaneous vertebroplasty after $\geq 2$ weeks of ineffective conservative therapy. A total of 27 patients (31 cases: 27 with one fracture, four with two each) were selected among the 57 cases with fractures in the thoracic 12 (T12) and lumbar 1 and 2 (L1, L2) vertebrae induced by the compression fracture. Percutaneous vertebroplasty was performed using polymethylmethacrylate (PMMA) in patients who did not experience improvement after adequate conservative therapy.

Compression ratio was measured in all patients at initial diagnosis using simple radiography and MRI. The compression ratio of the two images was evaluated at initial diagnosis, on the day of the surgery, and 6 months and more than 1 year after surgery. The percentage of the lowest height at the fractured vertebrae body using the mean upper and lower vertebral body's lowest height of the lesion was used for the compression ratio calculation ${ }^{12}$. When the upper or lower vertebral body had previous compression fractures, the next highest or lowest vertebral body height was used for the calculation. T1-weighted images (T1WI) were used for the MRI analysis. Cobb angle (the interior angle between the superior endplate of the ascending vertebral body and the inferior endplate of the descending vertebral body) was measured to determine the angulation deformity ${ }^{12)}$.

To analyze the progression of compression fracture according to the compression ratio difference of the two images, the mean compression ratio difference between the initial radiograph and MR image of $8.1 \%$ was set as the baseline to divide the patients into two study groups.

The progression of the compression ratio and the compre- ssion ratio difference of the two images were verified. The degree of pain was evaluated preoperatively, postoperatively, and at the follow-up examination using the VAS. BMD, cement injection dosage during vertebroplasty, and a history of diseases such as diabetes and hypertension were also verified.

\section{RESULTS}

The patient group included a total of 31 cases, including7 men (22.6\%) and 24 women (77.4\%) with a mean age of $73.0 \pm 7.1$ (range, 58-88) years. There were seven cases of compression fracture in the T12 area (one of simultaneous fracture in T9), 11 in the L1 area, nine in the L2 area (two of simultaneous fracture in $\mathrm{L} 3$, one in $\mathrm{L} 4)$. The mean $\mathrm{BMD}$ value was$3.1 \pm 1.3$ (range, -5.7 to -1.3 ).

The demographic characteristics of the entire patient group are shown in Table 1 . The mean compression ratio difference between the radiography and MR images was $8.1 \%$ at initial diagnosis. The 20 cases with a compression ratio difference $<8.1$ were classified into Group A and the 11 cases with a compression ratio difference $>8.1$ were classified into Group B. The characteristics of each group are shown in Table 2 . No significant differences were seen in sex, BMD, PMMA dosage, diagnosis, treatment period, or medical history (hypertension, diabetes, osteoporosis) with the exception of age between groups.

The difference in compression ratio of the initial radiography and MRI was significantly smaller in group A, and the change seen over time also revealed that the progression was 
Lee $\mathrm{SH}$ et al.

Table 2. Demographic characteristic of each group

\begin{tabular}{|c|c|c|c|}
\hline Criteria & $\begin{array}{c}\text { Group } A(<8.1) n=20 \\
M \pm S D, n(\%)\end{array}$ & $\begin{array}{c}\text { Group } B(>8.1) n=11 \\
M \pm S D, n(\%)\end{array}$ & p-value \\
\hline Age & $75.20 \pm 5.38$ & $69.00 \pm 8.23$ & 0.017 \\
\hline \multicolumn{4}{|l|}{ Sex } \\
\hline$M(n=7)$ & $3(15.0)$ & $4(36.4)$ & 0.173 \\
\hline$F(n=24)$ & $17(85.0)$ & $7(63.6)$ & 0.210 \\
\hline $\mathrm{BMD}$ & $-3.37 \pm 1.37$ & $-3.05 \pm 0.79$ & 0.430 \\
\hline PMMA dosage & $4.10 \pm 0.72$ & $4.27 \pm 0.65$ & 0.513 \\
\hline Diagnosis and treatment Period (days) & $13.15 \pm 5.24$ & $12.64 \pm 5.12$ & 0.794 \\
\hline
\end{tabular}

$\mathrm{BMD}$, bone mineral density; PMMA, polymethylmethacrylate.

Table 3. Characteristics of the compression ratios for each group

\begin{tabular}{|c|c|c|c|c|c|}
\hline Criteria & $\begin{array}{c}\text { Initial MRI } \\
M \pm S D\end{array}$ & $\begin{array}{c}\text { initial } \\
M \pm S D\end{array}$ & $\begin{array}{l}\text { postOP } \\
M \pm S D\end{array}$ & $\begin{array}{l}\text { 6-month } \\
M \pm S D\end{array}$ & $\begin{array}{l}1 \text { year } \\
M \pm S D\end{array}$ \\
\hline Group A & $22.65 \pm 14.42$ & $26.45 \pm 14.81$ & $28.05 \pm 15.12$ & $33.50 \pm 14.64$ & $32.35 \pm 13.86$ \\
\hline Group B & $16.18 \pm 8.47$ & $31.91 \pm 11.24$ & $33.09 \pm 5.63$ & $41.00 \pm 10.13$ & $42.27 \pm 8.33$ \\
\hline $\mathrm{p}$-value & 0.127 & 0.297 & 0.194 & 0.143 & 0.019 \\
\hline Difference & 6.47 & 5.46 & 5.04 & 7.50 & 9.92 \\
\hline
\end{tabular}

Table 4. Characteristics of VAS for each group

\begin{tabular}{lllll}
\hline \hline Criteria & \multicolumn{1}{c}{$\begin{array}{c}\text { initial } \\
(\mathrm{M} \pm \mathrm{SD})\end{array}$} & $\begin{array}{c}\text { post OP } \\
(\mathrm{M} \pm \mathrm{SD})\end{array}$ & $\begin{array}{c}6 \text { months } \\
(\mathrm{M} \pm \mathrm{SD})\end{array}$ & $\begin{array}{c}1 \text { year } \\
(\mathrm{M} \pm \mathrm{SD})\end{array}$ \\
\hline Group A & $7.10 \pm 1.62$ & $6.40 \pm 1.57$ & $5.65 \pm 1.66$ & $4.25 \pm 2.38$ \\
Group B & $6.27 \pm 0.79$ & $5.64 \pm 0.67$ & $4.73 \pm 0.79$ & $3.18 \pm 0.98$ \\
p-value & 0.066 & 0.070 & 0.045 & 0.091 \\
\hline
\end{tabular}

Table 5. Characteristics of Cobb's angle for each group

\begin{tabular}{lcccc}
\hline \hline Criteria & initial & postOP & 6 months & 1 year \\
& $M \pm S D$ & $M \pm S D$ & $M \pm S D$ & $M \pm S D$ \\
\hline \hline Group A & $8.06 \pm 7.30$ & $8.41 \pm 7.17$ & $10.27 \pm 8.43$ & $13.74 \pm 8.42$ \\
Group B & $12.34 \pm 13.39$ & $10.22 \pm 12.12$ & $14.56 \pm 12.19$ & $16.31 \pm 13.47$ \\
p-value & 0.256 & 0.604 & 0.257 & 0.516 \\
\hline
\end{tabular}

much slower compared to group B (Table 3). Actually, compression ratio difference of group $B$ between initial and last follow-up time with radiograph, showed more collapse progression than that of group A (5.46\% versus 9.92\%). Therefore we can assume that difference of initial compression ratio between standing radiography and supine MRI may influence the prognosis and overall progression of the compression in the fracture.

In addition, group B showed a considerable decrease in Cobb's angle, postoperatively. From this data we may deduce that a greater initial compression ratio serves as an opportunity to achieve a greater degree of correction, which leads us to believe that a greater initial compression ratio gives us

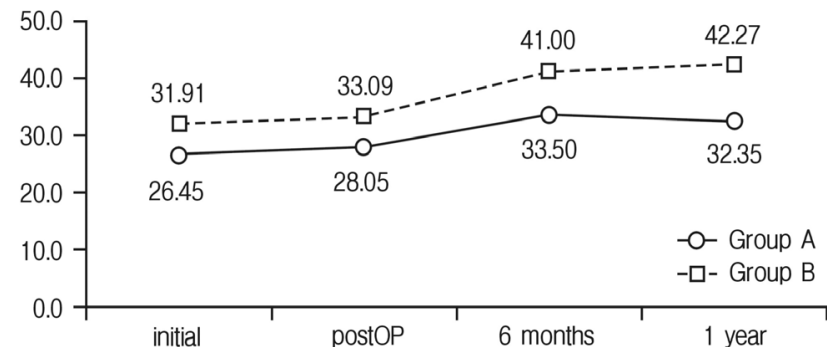

Fig. 1. Comparison of the compression ratio on radiography between groups by time.

room for greater reduction. Representative patients of group $\mathrm{A}$ and $\mathrm{B}$ are described in Fig. 4, 5.

No significant difference in VAS was seen between groups (Table 4). Also, no significant difference in Cobb angle was seen between groups (Table 5). Fig. 2 and 3 show a schematic of the differences in these variables between the two groups.

\section{DISCUSSION}

Percutaneous vertebroplasty, a surgical procedure involving the injection of PMMA into a collapsed vertebral body, was first described in 1987 by Pierre Galibert and Hervé Deramond for the treatment of symptomatic or aggressive vertebralangioma $^{2,5)}$. The use of vertebroplasty to treat benign or malignant diseases has been widely reported ${ }^{8)}$. It is already well known that percutaneous vertebroplastyis associated with good 
outcomes in patients with OVCF and relieves pain and reinforce weakened vertebrae in the immediate postoperative period especially ${ }^{5,10)}$. Other studies had reported that the vertebral height or focal kyphotic angle were also improved rightafter surgery ${ }^{3)}$. In almost cases of vertebral compression fractures, the treatments primarily include bed rest, pain control, adjunct wearing, and physical support. If the pain persists or the compression ratio increases despite such effort, percutaneous vertebroplasty in which bone cement is fused into the vertebral body can be considered ${ }^{4)}$. Also, in the fracture ununion with persistent mobility, cleft margins become increasingly sclerotic and more apparent radiographically with time ${ }^{13)}$.

According to the Korean Health Insurance Review \& Assessment Service, the following patients can be treated with

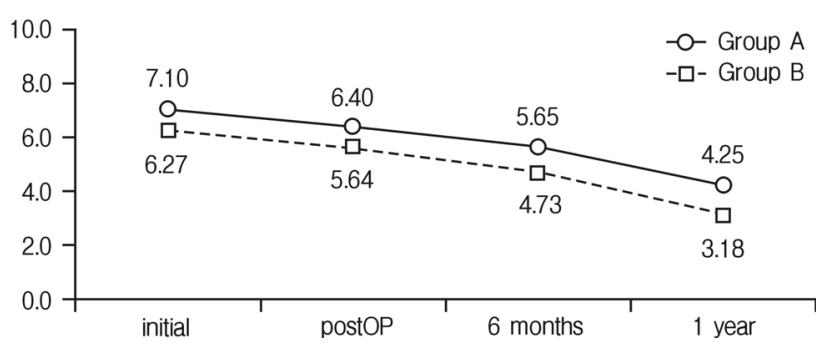

Fig. 2. Visual analog score (VAS) comparison between groups by time.

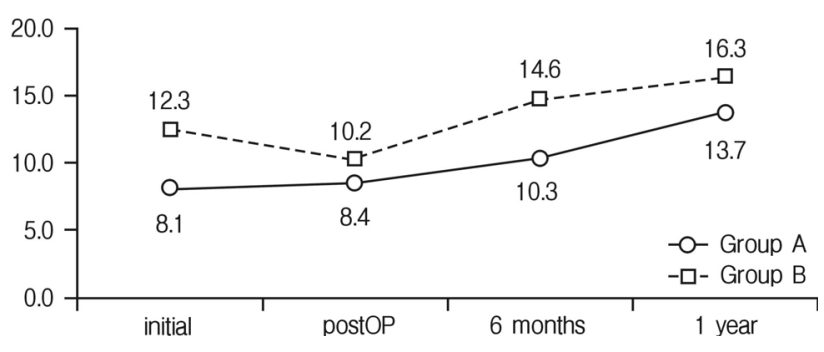

Fig. 3. Cobb's angle comparison between groups by time.
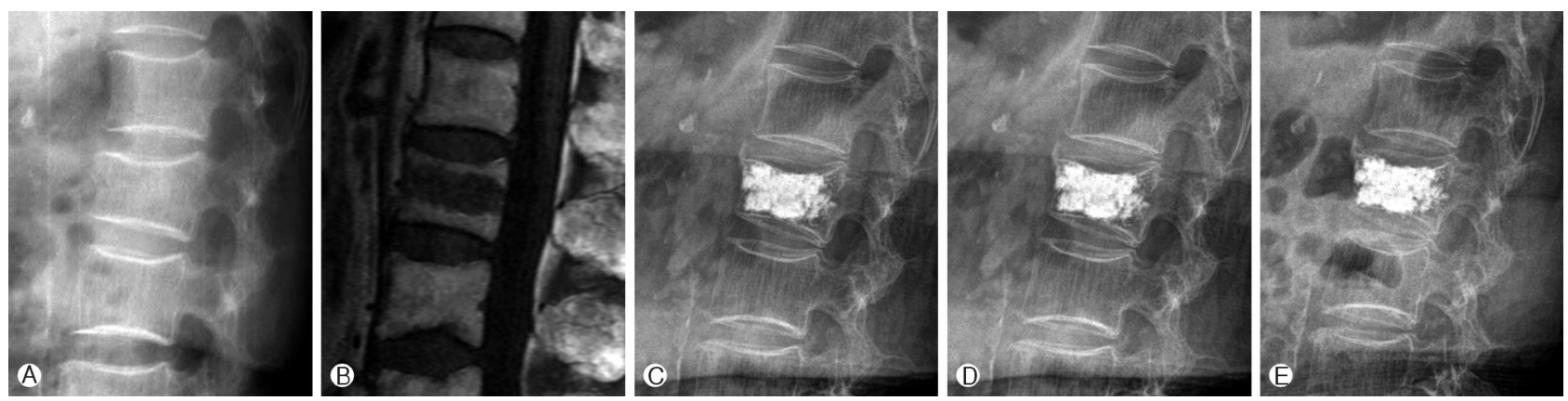

Fig. 4. (A) initial radiograph, $(B)$ initial MRI, (C) postoperative radiograph, (D) follow up radiograph after 6 months, (E) the last follow up radiograph. In group A, An 88-year-old woman was admitted with back pain after a fall. A compression fracture of the $\mathrm{L} 2$ vertebra was diagnosed using MRI, and vertebroplasty was performed since the patient was aged $>80$ years. Her BMD was -4.4 , and the initial compression ratios of the radiographs and MR images were $12 \%$ and $7 \%$, respectively (5\% simple difference). The compression ratios of the radiograph were $11 \%$ postoperatively, $24 \%$ after 6 postoperative months, and $25 \%$ after 1 year.
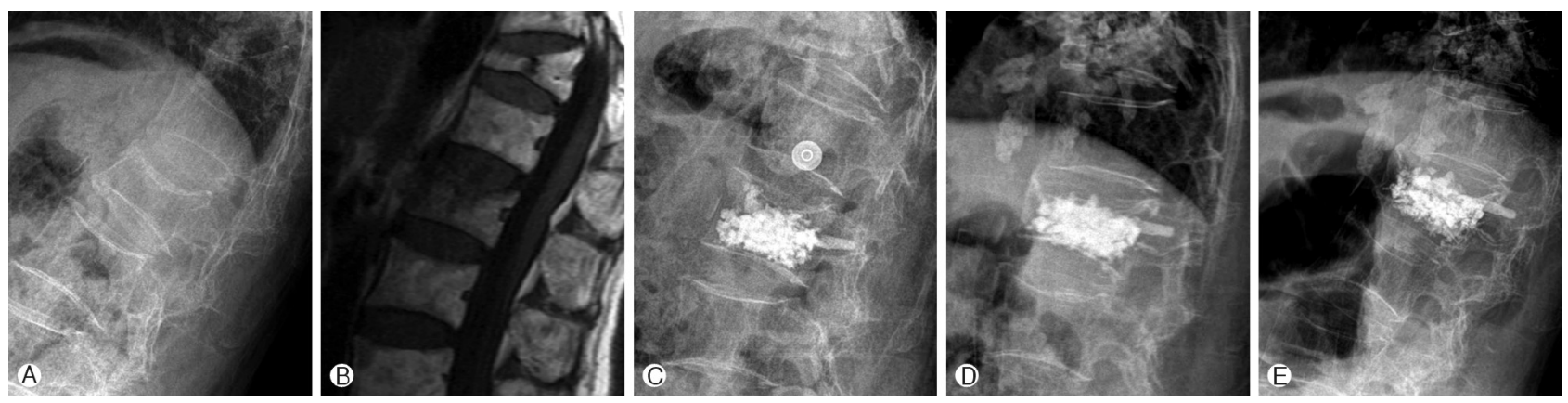

Fig. 5. (A) initial radiograph, $(B)$ initial MRI, (C) postoperative radiograph, (D) follow up radiograph after 6 months, (E) the last follow up radiograph. In group B, a79-year-old woman was admitted with back pain after a fall. A compression fracture of the L1 vertebra was diagnosed using MRI. Vertebroplasty was performed after 2 weeks of conservative treatment. The patient's BMD was -5.6 , and the compression ratios of the initial radiograph and MR image were 35\% and 20\%, respectively (15\% simple difference). The compression ratios on radiography during the follow-up examination were 17\% postoperatively, 36\% after 6 postoperative months, and $37 \%$ after 1 year. 
vertebroplasty: patients with persistent severe back pain even after at least 2 weeks of active conservative treatment (those with pneumonia, thrombophlebitis, uncontrolled diabetes, or chronic renal failure requiring dialysis, as well as the elderly aged $>80$ years may receive early surgical treatment); patients with fractures caused by cancer; and patients with Kummel's disease.

There are some studies ranged over clinical correlation between fractures and positions. Meng-Huang Wu et al. had reported that the vertebral height of severely collapsed compression fractures increased on supine lateral radiographs (SuLR) compared with standing lateral radiographs $\mathrm{StLR}{ }^{14)}$. McKiernan et al. reported that there was a strong positive correlation between the preoperative difference in vertebral height ratio between preoperative StLR and SuLR and the postoperative restoration in vertebral height ratio comparing preoperative StLR with postoperative $\mathrm{StLR}^{6}$. In our study, the difference in the two images is thought to be a result of the different positions used for standing radiography and supine MRI. However, this difference does not imply a faster progression of the compression ratio; therefore, the expansion seen on MRI may not be of significance. In addition, irrespective of the differences in the radiography and MRI findings, the compression ratio shows similar differences in progression rate (Table 3 and Fig. 1). Thus, the compression ratio calculated from the initial simple standing radiography may be more important as a prognostic factor for lesion progression than the differences in the simple radiography and MRI findings. Thus, we believe that the compression ratio calculated after standing radiography can serve as a better treatment guideline than the compression ratio calculated after MRI considering that the compression ratio of the two images may affect the compression ratio difference between the initial and final radiographs; however, the difference was not statistically significant owing to the small number of subjects in this study. Further more, re-evaluation of the difference between the mean VAS score and Cobb angle of the two groups is thought necessary, although no significance was observed in this study.

Another reason for the difference in the compression ratio between the standing radiography and supine MRI would be that radiography measures the lowest height of the vertebral body, whereas MRI measures the upper and the lower vertebral body heights at the lowest image of the lesion from the sagittal view. The image in the MRI could differ from the upper and the lower vertebral body height in the radiographs. Although the difference in the compression ratios of the two images and lesion progression in this study were not significant, considering the possibility of compression fracture progression or relapse during the follow-up period after treatment and the instability and decreased robustness in the vertebral body in the presence of a large compression ratio difference, further studies on early (with in 2 weeks of initial diag- nosis) vertebroplasty are necessary. Attempting re-expansion during conservative treatment at the time of the initial diagnosis, securing more physiological curvature during treatment, using the bone cement accordingly, or considering other supplementary means such as educating and encouraging patients to wear adjunct supports after treatment are other factors to be considered, since the compression ratio of the radiography at initial diagnosis of the OVCF determines the lesion progression. Disease progression may occur despite appropriate early treatment and regular follow-up examinations. To maintain optimal peak bone mass in patients with osteoporosis, appropriate nutritional intake such as calcium and vitamin D is recommended and patients should be urged not to smoke or drink ${ }^{11}$.

Although a thoracolumbar adjunct support, osteoporosis drug treatment, and exercise are prescribed for 3-4 months to prevent and treat new compression fractures resulting from percutaneous vertebroplasty or chronic compression fractures, the incidence of vertebral compression fractures continue to increase in elderly patients with severe osteoporosis ${ }^{1}$. Further more, one study with regular follow-up examinations showed that vertebroplasty does not prevent decreases in vertebral body height but maybe helpful for controlling pain ${ }^{97}$. A study has reported that exercise to fix posture and increase flexibility, such as yoga, can aggravate fractures in patients with osteoporosis $^{7}$. Aggressive exercise and fall prevention education to prevent fractures and regular BMD assessment in menopausal women or men aged $>70$ years are considered necessary. Exercise education, regular simple radiography, and osteoporotic treatment for patients with a medical history of osteoporotic vertebral fractures are also necessary ${ }^{1)}$.

\section{CONCLUSION}

There were no significant differences in the baseline characteristics with the exception of age between the two groups. There were also no significant differences between the periodic compression ratio of radiography, VAS, Cobb's angle at the initial time of diagnosis and the last follow up. But, a greater compression rate in the initial radiograph also resulted in a greater compression rate in the follow-up radiograph. Therefore, we suggest that it is important to check the initial standing simple radiograph, as well as supine MRI, for predicting collapse progression after vertebroplasty.

\section{REFERENCES}

1. Chae SU, Kim YJ, Choi BS, Park JI, Choi DH: The association between the bone mineral density and spinal osteoarthritis in osteoporotic thoracolumbar compression fractures. Korean J Bone 
Metab 18(2):119-124, 2011

2. Galibert P, Deramond H, Rosat P, Le Gars D: A method for certain spinal angiomas: percutaneous vertebroplasty with acrylic cement. Neurochirurgie 33:166-168, 1987

3. Kim JH, Yoo SH, Kim JH: Long-term Follow-up of Percutaneous Vertebroplasty in Osteoporotic Compression Fracture: Minimum of 5 Years Follow-up. Asian Spine J 6(1):6-14, 2012

4. Klazen CAH, Lohle PNM, de Vries J, Jansen FH, Tielbeek AV, Blonk MC, et al: Vertebroplasty versus conservative treatment in acuteosteoporotic vertebral compression fractures (Vertos II): an open-label randomised trial. Lancet 376:1085-1092, 2010

5. Legroux-Gerot I, Lormeau C, Boutry N, Cotten A, Duquesnoy B, Cortet B: Long-term follow-up of vertebral osteoporotic fracturestreated by percutaneous vertebroplasty. Cin Rheumatol 23(4): 310-317, 2004

6. McKiernan F, Jensen R, Faciszewski T: The dynamic mobility of vertebral compression fractures. J Bone Miner Res 18(1): 24-9, 2003

7. Mehrsheed S: Yoga spinal flexion positions and vertebral compression fracture in osteopenia or osteoporosis ofspine: case series. Pain Pract 13(1):68-75, 2013

8. Nam HGW, Jeong JH, Shin IY, Moon SM, Hwang HS: Clinical effects and radiological results of vertebroplasty: over a 2-year follow-up period. Korean J Spine 9(4):334-339, 2012

9. Oh YS, Lee KY, Seo JY, Kim SH: Long term results of vertebroplasty in the treatment of osteoporotic compression fracture. J Korean Soc Spine Surg 20:86-91, 2013

10. Peh WCG, Gilula LA, Peck DD: Percutaneous vertebroplasty for severe osteoporotic vertebral body compression fractures. Radiology 223:121-126, 2002

11. Rao RD, Singrakhia MD: Painful osteoporotic vertebral fracture pathogenesis, evaluation, and roles of vertebroplasty and kyphoplasty in its management. J Bone Joint Surg Am 85-A(10):20, 2003

12. Son $\mathrm{KH}$, Chung NS, Jeon CH: Measurement of Vertebral Compression and Kyphosis in the Thoracolumbar and Lumbar Fractures. J Korean Soc Spine Surg 17(3):120-126, 2010

13. Toyone T, Toyone T, Tanaka T, Wada Y, Kamikawa K, Ito M: Changes in Vertebral Wedging Rate Between Supine and Standing Position and its Association With Back Pain: A Prospective Study in Patients With Osteoporotic Vertebral Compression Fractures. Spine (Phila Pa 1976) 31(25):2963-6, 2006

14. Wu MH, Huang TJ, Cheng CC, Li YY, Hsu RW: Role of the supine lateral radiograph of the spine in vertebroplasty for osteoporotic vertebral compression fracture: a prospective study. BMC Musculoskeletal Disord 11:164, 2010 